\title{
UN NUEVO EQUILIBRIO ENTRE POLÍTICAS PÚBLICAS, ÉTICA Y UNIVERSIDAD MODERNA
}

\author{
Eduardo Dockendorff V. \\ Instituto de Asuntos Públicos \\ Universidad de Chile
}

Desde el momento que la política se sirve de las demás ciencias prácticas y legisla sobre lo que debe hacerse y lo que debe evitarse, el fin que le es propio abraza los de todas las otras ciencias, al punto de ser por excelencia el bien humano. Y por más que este bien sea el mismo para el individuo y para la ciudad es, con mucho, cosa mayor y más perfecta la gestión y salvaguarda del bien de la ciudad. Es cosa amable hacer el bien a uno solo; pero más bella y más divina es hacerlo al pueblo y a las ciudades.

(Aristóteles, Ética Nicomaquea, 1094 b)

En pocos ámbitos la relevancia social y pertinencia de las universidades es más visible que en la producción de conocimiento para una mejor calidad de las políticas públicas o bien para mostrar caminos a la sociedad para mejorar la calidad de vida de las personas.

En las universidades humboldtianas, la producción y difusión del conocimiento se genera en las facultades o unidades académicas similares, normalmente de escasa relación entre sí. Ello reproduce un modelo muy fragmentado que sirve poco a las ciencias aplicadas, como lo son las políticas públicas, entre otras. Más aún, el arte del buen gobierno requiere todo el conocimiento. Sin embargo, como lo veremos, ni todo el conocimiento de la humanidad, ni de todas las universidades del mundo, hará que las políticas públicas sean mejores para la gente. Porque mientras las políticas públicas representan la carta de navegación, el devenir del trayecto lo hace el conductor a través del liderazgo.

Se ha dicho que "gobernar es una afirmación de la voluntad, un intento de ejercer control, de modelar el mundo. Las políticas públicas son instrumentos de esta resuelta ambición" (ver Fierro, 2008). Gobernar es tomar firmemente las riendas de 
esa constelación de intereses que se llama comunidad política y llevarla a buen destino, llamado Bien Común. Se trata de realizar la difícil tarea a través de la cual hombres y mujeres, quienes tienen ideas, intereses y capacidades diversas, deliberan y finalmente resuelven pacífica y democráticamente, cuál es la mejor forma de vivir en común.

Las políticas públicas son justamente una de las maneras como los gobiernos buscan responder a las necesidades sociales que se han expresado en demandas políticas hacia el Estado. Responder bien no sólo significa mejorar la calidad de vida de los habitantes de una sociedad sino que aumentar la legitimidad de su forma de gobierno, en nuestro caso, la democracia. Puesto que si bien los pueblos adhieren activamente a su democracia por cercanía con ciertas doctrinas, discursos, historias y liderazgos; no es menos cierto que las democracias deben sumar a esta legitimidad difusa una específica, fundada en la satisfacción de las demandas más hondamente sentidas por el mayor número de ciudadanos (Lahera, 2002: 100).

La importancia de las políticas públicas ha obligado al saber científico a preocuparse de ellas.Y como nos lo advertía Aristóteles, ello trae aparejado el problema del debate conceptual, tanto teórico como metodológico. Como lo ha señalado un destacado sociólogo: "Este es el caso de la apropiación de la noción de políticas públicas que se ha hecho desde la economía, la sociología, la ciencia política y la administración pública, entre otras. Para la economía, el énfasis está dado en los factores económicos que influyen en las políticas públicas, tales como el crecimiento económico, la productividad y el empleo. Para la sociología, en cambio, el énfasis gira en torno al conjunto de demandas que pueden ejercer la comunidad y los grupos en el proceso de construcción de las políticas públicas. La ciencia política, por otra parte, enfatiza el papel que juega el proceso político en la generación e implementación de las políticas públicas. En el caso de la administración pública, se enfatiza la gerencia de los programas públicos como una parte importante del proceso de desarrollo de las políticas públicas; y así sucesivamente" (Fierro, 2008)

Desde el punto de vista académico puro, estaría todo bien hasta aquí. Sin embargo cuando se trata de ejecutar una acción pública (por ejemplo: el Transantiago, la construcción de generadoras de energía, el Plan AUGE o la Reforma Educacional), las disciplinas no deben ni pueden dejar de dialogar entre sí. La historia del desarrollo de los países está plagada de desaciertos que provienen de esta obsesión sectorialista de las disciplinas autocontenidas. En el diseño de las políticas públicas del mundo moderno debemos seguir una regla de oro, cual es que ninguna política pública puede ser contenida por una sola disciplina. Ninguna. Es tanto así que, por ejemplo, 
una eficiente política de transporte urbano -antes que pensar sólo en vías, flujos y medios- debería empezar por una inteligente política de localización de actividades y población en la ciudad para incidir en el volumen de viajes. De modo similar, una eficiente política de salud, por ejemplo para combatir la obesidad, antes que pensar en la respuesta sectorial curativa, debería empezar por una inteligente política de vida sana, combinada con otra de desarrollo agropecuario, consistente con una de alimentación y probablemente otra de desarrollo deportivo, etc.

Por ello debemos buscar una aproximación interdisciplinaria hacia su estudio, particularmente en cómo son formuladas e implementadas. Lahera señala que las políticas públicas debieran entenderse como "cursos de acción y flujos de información relacionados con un objetivo público definido en forma democrática; los que son desarrollados por el sector público y, frecuentemente, con la participación de la comunidad y el sector privado" (Lahera, 2002: 13 y 18).

Es mediante las políticas públicas como los gobiernos deciden cómo, cuándo y dónde proporcionar bienes y servicios a la sociedad. Se define el problema a abordar, se trazan los objetivos, se definen los medios e instrumentos a utilizar, se mandatan organizaciones gubernamentales o no gubernamentales para su realización, se asignan recursos, se ejecutan las decisiones, se evalúan sus impactos. El Instituto de Asuntos Públicos de esta Universidad tiene nada menos que esta descomunal ambición: coordinar los esfuerzos de investigación y extensión que produzcan pensamiento crítico al servicio de los asuntos públicos que requiera el desarrollo del país.

Las universidades pueden recuperar parte de su legitimidad social, si son capaces de suministrar orientaciones y ciencia aplicada al bienestar de la sociedad, pero no podrán cumplir con otro requisito del buen gobierno, el cual descansa en las cualidades del liderazgo

\section{La vieja ética para un nuevo liderazgo}

Tanto en el mundo de las políticas públicas, como en los negocios, ha primado durante todo el siglo XX y lo que lleva el actual lustro, decisivamente los enfoques positivistas. En efecto, en vez de tratar de emular a las ciencias naturales o buscar legitimidad en las ciencias exactas, deberíamos haber asegurado que los líderes se plantearan mejor preguntas como: ¿Para dónde vamos? ¿Quiénes ganan, o quienes pierden conforme qué arreglo del poder? ¿Es socialmente deseable lo que está ocurriendo (Ej. cambio climático)? ¿Qué hacer entonces? (Flyvbjerg, 2001). 
Esta deformación cognitiva arranca del hecho que normalmente los líderes para comunicar sus propósitos, sus políticas o sus decisiones, recurren al conocimiento explícito, esto es aquel que puede ser codificado, medido, estandarizado y sancionado objetivamente, por ejemplo, a través de indicadores. En la crisis subprime de 2010, los conspicuos ejecutivos en Wall Street creyeron que podían acumular riesgos cada vez más grandes, usando números, datos y fórmulas científicas desestimando el simple buen criterio para evaluar cada crédito en su mérito, uno por uno, o sea al conocimiento tácito. Algo similar ocurre con la industria automotriz, la que descansa en las ofertas de incentivos financieros, antes que las necesidades de los clientes (Nonaka \& Hirotaka, 1999). En este sentido:

Depender sólo del conocimiento explícito impide que los líderes se adapten al cambio. El enfoque teórico, científico y deductivo, supone un mundo independiente del contexto y busca respuestas universales y predictivas. Sin embargo todos los fenómenos sociales son dependientes del contexto y no tiene sentido analizarlos a menos que se tomen en cuenta los objetivos, valores e intereses de las personas junto con las relaciones de poder que hay entre ellas (Nonaka \& Hirotaka, 2001).

Las políticas públicas son una forma de construir el futuro, pues éstas no sólo deben apuntar a satisfacer necesidades o resolver problemas actuales, sino muy especialmente a aprovechar las potencialidades subyacentes en cada sociedad. La creación de valor futuro entonces debe ir mucho más allá del partido, de la coalición, o del grupo de interés o la empresa. Debe mirar el bien común. Los líderes políticos deben preguntarse siempre si sus decisiones son tan buenas para la sociedad como para sus partidos o coaliciones. Lo propio deberían hacer los ejecutivos respecto de sus empresas. Es importante que las organizaciones de la sociedad aprendan a trabajar siempre para un objetivo de más alcance que su propia suerte institucional o social. Las organizaciones, partidos, empresas, asociaciones deben asumir la misión de crear bienes superiores - públicos- para toda la sociedad. Las agrupaciones que no logren crear valor social, político o económico, están condenadas a desaparecer, tarde o temprano.

En Japón, estudios recientes han demostrado que, para que exista una relación funcional y armónica -y no de conflicto- entre sociedad y organización intermedia se requiere no sólo conocimiento explícito y tácito, sino a una forma olvidada de éste que se podría llamar sabiduría práctica. La sabiduría práctica es el conocimiento adquirido por la experiencia que permite hacer juicios prudentes y actuar de acuerdo a la situación actual, guiados por los valores y la moral (Nonaka \& Hirotaka, 2001).

Curiosamente este sentido de la responsabilidad social no es atributo privativo de determinadas culturas sino del pulso ético y el sentido histórico de la naturaleza humana 
desde siempre: Lo que aquí se denomina sabiduría práctica fue acuñado hace más de 20 siglos por Aristóteles en Ética Nicomaquea, bajo la expresión frónesis ${ }^{1}$, la cual junto a la sabiduría metafísica (esotérica) y sabiduría práctica, constituían las tres formas de sabiduría.

En Occidente haríamos bien preguntarnos por qué Japón -a pesar de su reciente catástrofe natural, con crisis nuclear incluida- no sufre la crisis de confianza que sí ensombrece la convivencia social y política en los EE.UU. Pareciera ser aquel uno de los países donde la llamada frónesis fuese más paradigmática. Muchas veces en Occidente las coaliciones políticas, las empresas y grupos de interés, suelen comportarse pensando sólo en sí mismas porque "después de mí, el diluvio".

En el mundo de hoy, testigo de desequilibrios económicos y recurrentes crisis políticas enumeradas al comienzo, ha fallado el liderazgo como nunca antes. Los líderes están paralogizados, porque no saben adónde ir. Cuando se dice genéricamente que está fallando la política, más que los modelos o las políticas públicas, se está afirmando lo mismo. Es la práctica de las decisiones políticas la que se desrieló de su eje ético y con ello del principio rector de la armonía social.

A su vez, el liderazgo en el ámbito científico no ha salido indemne de esta tendencia pues se ha parapetado en sus certezas cómodas, por temor a desmoronar los sistemas institucionales que les proveen los medios para subsistir, y no asumen riesgos políticos sea para denunciar o para explorar nuevas respuestas, las cuales necesariamente incomodarán a muchos intereses. Sin ética (pública), la política se deja atrapar por los intereses inmediatos de sus actores y la ciencia por sus temores a cuestionar el statu quo que le da de comer.

Los líderes políticos siguen creyendo que el objetivo de su quehacer se agota en el destino de su coalición o su propio partido y que la ambición es buena mientras la logren disimular ante los electores; los ejecutivos siguen creyendo que el objetivo de sus empresas es hacer negocios y que la codicia es buena mientras los reguladores estatales no la descubran; los científicos siguen creyendo que la misión de sus facultades o departamentos es producir el conocimiento que necesita la sociedad y que es culpa de los políticos - probablemente ignorantes e iletrados-que les reduzcan a las universidades los fondos institucionales.

Cuando los líderes abandonan la ética pública como principio rector, terminan por hacer de los intereses de su institución, empresa o partido político, el epicentro de

Según Aristóteles, Frónesis es la capacidad real de deliberar rectamente sobre lo que es bueno y conveniente para el ser humano (Ética Nicomaquea,VI.6). 
sus prioridades. La suerte del resto de la sociedad no es de su incumbencia. En un extremo, el asunto es ¿cómo voy ahí? o ¿cuánto gano yo aquí? Lo demás, me da lo mismo.

Si nosotros, por el contrario, antes que pensar en las oportunidades de nuestra empresa, o los beneficios de mi organización o gremio, en la sobrevivencia de mi coalición o partido político, o la rentabilidad sólo de mi negocio, pusiésemos la atención en el bien común de la sociedad y cómo mi institución, universidad, partido político, empresa o asociación, se hace funcional a dicho propósito, estaremos favoreciendo los intereses de mi microcosmos con aquel de la sociedad a la que pertenecemos.

¿Qué es aquello que nos lleva a subordinar nuestros intereses particulares o grupales al de la comunidad total, al Bien Común, en suma? Pienso que la ética. Ella representa el más poderoso y magnífico atributo del sentido colectivo de la naturaleza humana, que es esencialmente ética. En Occidente la ética se ha constreñido demasiado a la esfera del individuo y su realidad. Es hora de volver a hacer de nuestras instituciones, universidades, empresas, partidos políticos, instrumentos cuyos objetivos sean funcionales a los objetivos superiores de la sociedad. De otro modo, las políticas públicas no serán más que meras declaraciones de buenas intenciones, o puros decorados en los programas de gobierno para seducir electores. Sin ética pública no habrá políticas públicas de calidad, por más rigurosos que sean sus fundamentos científicos.

Por último, es este espíritu el que ha animado al Instituto de Asuntos Públicos de la Universidad de Chile a convocar a este grupo de académicos que tienen la enorme tarea de construir conocimiento multidisciplinario, desde la excelencia académica, para reencontrar a la Universidad con las grandes demandas de la sociedad chilena. 


\section{Referencias bibliográficas}

Fierro, Jaime (2008). Políticas públicas regionales: una guía teórico-metodológica. Santiago: Departamento de Políticas y Descentralización, División de Políticas y Estudios, Subsecretaría de Desarrollo Regional y Administrativo.

Lahera, Eugenio (2002). Introducción a las Políticas Públicas. Santiago: Fondo de Cultura Económica.

Flyvjerg, Bent (2001). Making Social Science Matter. Reino Unido: Cambridge University Press.

Nonaka, Ikujiro \& Takeuchi, Hirotaka (1999). La organización creadora del conocimiento. México: Oxford University Press.

Nonaka, Ikujiro \& Takeuchi, Hirotaka (2011). "El líder sabio". Harvard Business Review, Vol. $89, \mathrm{~N}^{\circ} 4$. 